\title{
PORTAL TECHNOLOGY FOR INTEGRATED, USER-CENTRIC UNIVERSITY INFORMATION SYSTEMS
}

\author{
Marko Bajec, Viljan Mahnič and Marjan Krisper \\ University of Ljubljana, Faculty of Computer \& Information Science, Trzaska 25, \\ 1000 Ljubljana,Slovenia
}

Abstract: The paper describes a project that was launched as the first step towards the realisation of the Information Systems (IS) strategy plan developed for the University of Ljubljana. The strategy plan revealed many weaknesses and disadvantages of the current university IS. One of them was the lack of the possibility to utilize e-business technology. As a response the University of Ljubljana decided to renovate the current Student records IS using a technology which seems to be very promising in developing integrated, usercentric IT solutions. In the paper, we shortly introduce the strategy plan and discuss some characteristics of the portal technology. In more detail we focus on the renovation of the Student records IS. In conclusion, we expose some difficulties that we had to deal with during the project.

Key words: University information systems, portal technology, e-business, student records

\section{INTRODUCTION}

The University of Ljubljana is with its 26 member institutions the largest university in Slovenia. It has approximately 59,000 students, more than 2,600 teaching and research personnel and about 1,250 administrative staff. According to its finances, the University of Ljubljana is a kind of state university funded by the Ministry of Education, Science and Sport. Its rather distinguishing characteristic is that it permits member institutions to have a great autonomy in the way of their work. In addition, the member

The original version of this chapter was revised: The copyright line was incorrect. This has been corrected. The Erratum to this chapter is available at DOI: 10.1007/978-0-387-35689-1_19 
institutions are also financially independent, as they receive funds directly from the ministry. In the future, however, this is going to change. A number of activities will be centralised and led by the university. All the correspondence with the ministry will be coordinated centrally by the university as a whole. From then on, the university will make necessary contracts with the ministry and will be entitled and responsible for receiving and distributing funds to its members.

Another important change that is affecting the operation of the university and its member institutions is based on the new approach in developing curricula. The university is adopting the so-called credit system, which will allow students to choose among many courses, irrespectively of the institution where the courses are delivered. In the past, this was hardly possible, as the curricula ware rigid and only based on courses delivered at a single institution. The new curricula tend to be more flexible in this respect, which will consequently require a higher level of collaboration between the university members.

The aforementioned changes affect the university as a whole and require modifications in both university structure and operation. Consequently, this requires a redesign of the University IS (UIS) to meet the new objectives. The university responded to the expected changes and ordered the development of a strategy plan for a complete and integrated UIS. The project was started in August 2001 and was successfully finished five months later with a support of a complete university board (Krisper et al, 2001).

The strategy plan has revealed many weaknesses and problems of the current IS and proposed several solutions, including an architecture for the future UIS. To provide information at all organizational levels the architecture comprised a number of interconnected sub-systems. Some of them were required for each member institution (e.g. the Student records sub-system, Finance and accounting sub-system, Human resources subsystem, etc.), while others were supposed to support centralised activities and were therefore only expected to run at the university level or at the rector's office. According to the architecture the future UIS should be supported by a number of sub-systems, including a workflow system, data warehouse, document system and decision support system.

Another important element in the UIS architecture that drew our attention was a portal. When we were developing an idea of a desired UIS we realised that just having all the sub-systems developed and integrated into a working whole supported by communication infrastructure, data warehouse, document system and management system is maybe not enough. This only gives an infrastructure that holds all the information required for various users. What is missing is an appropriate and effective interface through 
which UIS users will be able to access the information. Not only administrative staff would require such an interface, but also students, teachers and managers expect to have a way to access the information they seek. In addition, UIS users do not want to have to search through all the systems and databases but they want to have access to the data that has been prepared for them.

For example, if I am a professor and I want to see how well the students did their examination in some course that I teach, I can use a report that is most likely provided in this regard in student records sub-system (in most cases professors still have to ask the staff to send them the report). Of course, I have to tell the system, who am I, what courses interests me etc. However, if I have been authenticated to the system, why wouldn't the system prepare this information for me? The system knows who I am and what my roles are, so it could provide me with personalised information. For example, about courses I am teaching, notices from students, etc. Moreover, the system could keep information about my requests and typical inquiries and in future provide me with an even more personalised interface.

We asked ourselves, who are typical UIS users and what they typically want from the system (in technical terms). We identified several groups of users, most notably teachers, researchers, administration staff, managers, students (current, prospective and alumni students) and interested public. Of course, they have different requirements and ideas of how the system should serve their everyday work, but there are some general features each of them needed. These are:

- To access the system from everywhere (not just from work, but also from home, conference, etc.)

- To not require a complex client software to access IS (instead they would like to use an internet browser, or even mobile phone or pocket computer)

- To access all information assets through a single entry point (they don't want to have a number of different systems, usernames, passwords, etc.)

- To get personalised information and services

- To access information and services in a secure way

Although there is no common definition of a portal, several IT professionals and companies like IBM, Delphi Group, Gartner Group, Meta Group, etc. seem to agree that these are all the features of a portal. They describe a portal as "an IT solution that provides a secure, single point of interaction with diverse information, business processes and people, personalized to a user's needs and responsibilities".

Portals are extremely popular today, not just in business but also in higher education. Today almost all universities are either developing or buying portal solutions for their needs (Cunin et al. 2002, Haselbacher 2002, 
Rio et al. 2002, Shaw et al. 2002, Gartner Group 2000a). JA-SIG (Java Special Interest Group) has even started a Portal Framework Project in which over 20 universities have been joined with an aim to develop a free, sharable portal for institutions of higher education (Olsen 2000, Gartner Group 2000b). The use of portals in higher education has also raised interests among researchers (Looney and Lyman 2000, Eisler 2000, Woods et al. 2002, Gartner Group 2000a, etc.).

In the rest of the paper, we explain our case of developing a portal solution to satisfy students', teachers' and staff information requirements. We describe a project that has taken the first step toward realization of the UIS strategy plan.

\section{RENOVATION OF THE STUDENTS RECORDS IS}

\subsection{Background}

At a university, the Student Records Office staff is usually responsible for all administrative tasks dealing with enrolment, examination schedules, examination records, degree records, and various statistical surveys showing student progress from year to year. In order to automate the aforementioned activities, a computer based student records IS (SRIS) was developed at the University of Ljubljana in 1994 (Mahnič and Vilfan 1995). Given the fact that the University of Ljubljana is extremely decentralized, each member institution (viz. faculty, academy or college) maintains its own IS, implemented in a local area network of personal computers sharing a common database.

Experience has shown that the system satisfies the basic needs of the Student Records Office staff, but lacks the possibility to utilize e-business technology. For example, students can enter their examination applications and requests for various official statements (e.g. a transcript of completed examinations) only from workstations within the faculty premises, but they cannot use these functions from their homes. During enrolment, they must still fill a special enrolment form instead of providing the corresponding data electronically. Similarly, teachers must inform the Student Records Office about examination dates and examination grades using special forms instead of entering the corresponding data directly in the computer database.

Considering the increasing demand for distant access of data, the new system should provide not only the administrative staff, but also students and teachers with all necessary information regarding the teaching process. Additionally, the system should simplify administrative tasks and reduce 
paperwork by the introduction of electronic business methods wherever appropriate. In such a way, a more efficient and better communication between all parties involved (viz. students, teachers, and administrative staff) will be achieved.

Since it has been found that the maintenance of examination schedules, examination applications, and examination results is the most critical part of the system, we decided to implement this part of the new system first, while other parts (viz. enrolment data and degree records) will be added later. Therefore, in this paper only the results of the first phase are described.

\subsection{Overview of requirements specification}

The Requirements Specification document (Mahnič 2001) specifies the establishment of a portal based on an Oracle database that will be customized to serve three different groups of end users, viz. teaching staff, administrative staff, and students. All functions will be accessible through World Wide Web, thus requiring only a Web browser on the user's side. Where appropriate, the same functions will also be implemented for WAP and SMS protocols.

We plan to put the new system into operation immediately after the completion of the first phase. This means that both systems, the old and the new one, will run in parallel until the old system is completely rebuilt. Therefore, special attention was devoted to the minimization of data interchange between the old database (implemented in Clipper) and the new one (implemented in Oracle). It was found that the update functions must also be included in the new system although at the beginning our intention was merely to disseminate information stored in the database. A complete list of functions considered for implementation in the first phase is shown in Table 8-1.

The F1 function enables the creation, updating and deletion of examination schedule data. At the University of Ljubljana the schedule of examinations is quite flexible, and is often subject to agreement between teachers and students. Therefore, this function is available not only to administrative staff, but to teachers as well (however, only for the subjects they teach). Each exam consists of two parts: written and oral. Functions F1 through F8 refer to the written part of examination while functions F9 to F13 deal with the oral part.

The examination schedule can be seen via the F2 function, which lists examination dates using different criteria (time period, subject etc.). F3 and F4 functions enable students to enter and cancel examination applications, respectively. The F3 function checks whether a student applied only for examinations that are on his course list as well as some other conditions (e.g. 
that the total number of examination attempts is below a set maximum, that students are billed if necessary etc. etc.). Experience has shown that some teachers also accept candidates who did not apply for an examination in time. In order to deal with such exceptions, the teaching and administrative staff is given the possibility to enter an examination application after the prescribed deadline. Similarly, teaching and administrative staff can delete an application if a student was unable to attend the exam due to illness etc.

The F5 function gives teaching and administrative staff the exact numbers of candidates for each examination, while function F6 produces lists of applicants. Results of the written part of examination (together with grades of seminar work that contribute to the final grade) are entered using function F7 and students are notified using function F8.

The F9 function enables the creation, updating, and deletion of examination times for oral examination, while function F10 lists these times using different criteria (time period, teacher, subject etc.). A student can apply for oral examination only if he/she has passed the written part of the exam. This condition is checked by function F11 that enables students to enter an examination application, while function F12 cancels an existing application. The F13 function produces lists of applicants. After the oral examination, a student is given the final grade, which can be entered in the system by the examiner or administrative staff (function F14). The F15 function provides a statistical survey of examination results that enables the comparison of results in different examination periods and serves as a basis for decisions dealing with the improvements of the study process.

The F16 function provides a student a record of all exams he/she passed and grades obtained. In this, way he/she has access to all data about his/her study that are recorded in the Student Records Office. Through function F17 students can send their requests for various official statements, e.g. student transcripts (report of examinations passed), and statement of enrolment.

Finally, the F18 function gives the teaching and administrative staff the possibility to send students various messages and notifications. The most important feature of this function is the possibility to define the subset of students that will receive information according to different criteria: the academic year, year of study, study program, courses taken, manner of studies (full-time, part-time), type of enrolment (first time, repeated enrolment) etc. 
Table -1. Functions to be implemented in the first phase

\begin{tabular}{|c|c|c|c|c|c|c|c|}
\hline ID & Function Description & Teachers & $\begin{array}{l}\text { Admin. } \\
\text { Stafi }\end{array}$ & Students & WEB & WAP & SMS \\
\hline$\overline{\text { F1 }}$ & $\begin{array}{l}\text { Maintenance of examination } \\
\text { schedules }\end{array}$ & $\checkmark$ & $\checkmark$ & & $\checkmark$ & & \\
\hline F2 & $\begin{array}{l}\text { Survey of examination } \\
\text { schedules }\end{array}$ & $\checkmark$ & $\checkmark$ & $\checkmark$ & $\checkmark$ & $\checkmark$ & \\
\hline F3 & Examination application & $\checkmark$ & $\checkmark$ & $\checkmark$ & $\checkmark$ & $\checkmark$ & \\
\hline F4 & $\begin{array}{l}\text { Cancellation of examination } \\
\text { application }\end{array}$ & $\checkmark$ & $\checkmark$ & $\checkmark$ & $\checkmark$ & $\checkmark$ & \\
\hline F5 & $\begin{array}{l}\text { Survey of number of } \\
\text { applications }\end{array}$ & $\checkmark$ & $\checkmark$ & & $\checkmark$ & & \\
\hline F6 & $\begin{array}{l}\text { Lists of candidates for } \\
\text { examination }\end{array}$ & $\checkmark$ & $\checkmark$ & & $\checkmark$ & & \\
\hline F7 & $\begin{array}{l}\text { Entry of results of the written } \\
\text { part of examination }\end{array}$ & $\checkmark$ & & & $\checkmark$ & & \\
\hline F8 & $\begin{array}{l}\text { Notification of results of the } \\
\text { written part of an exam }\end{array}$ & $\checkmark$ & & & $\checkmark$ & $\checkmark$ & $\checkmark$ \\
\hline F9 & $\begin{array}{l}\text { Maintenance of oral } \\
\text { examination schedules }\end{array}$ & $\checkmark$ & & & $\checkmark$ & & \\
\hline F10 & $\begin{array}{l}\text { Survey of oral examination } \\
\text { schedules }\end{array}$ & $\checkmark$ & & & $\checkmark$ & $\checkmark$ & \\
\hline F11 & $\begin{array}{l}\text { Entry of an oral exam } \\
\text { application }\end{array}$ & & & $\checkmark$ & $\checkmark$ & $\checkmark$ & \\
\hline F12 & $\begin{array}{l}\text { Cancellation of an oral exam } \\
\text { application }\end{array}$ & & & $\checkmark$ & $\checkmark$ & $\checkmark$ & \\
\hline F13 & $\begin{array}{l}\text { Lists of candidates for oral } \\
\text { examination }\end{array}$ & $\checkmark$ & & & $\checkmark$ & & \\
\hline F14 & Entry of the final grade & $\checkmark$ & $\checkmark$ & & $\checkmark$ & & $\checkmark$ \\
\hline F15 & $\begin{array}{l}\text { Statistical survey of } \\
\text { examination results }\end{array}$ & $\checkmark$ & $\checkmark$ & & & & \\
\hline F16 & List of passed exams & & $\checkmark$ & $\checkmark$ & $\checkmark$ & & \\
\hline F17 & $\begin{array}{l}\text { Requests for various official } \\
\text { statements }\end{array}$ & & & $\checkmark$ & $\checkmark$ & $\checkmark$ & \\
\hline F18 & $\begin{array}{l}\text { Messages to students: } \\
\text { send } \\
\text { receive }\end{array}$ & $\checkmark$ & $\checkmark$ & $\checkmark$ & $\checkmark$ & $\checkmark$ & $\checkmark$ \\
\hline
\end{tabular}

\section{PROBLEMS AND EXPERIENCES}

The biggest problem that we were facing during the project initiation was how to cover all the specifics of the 26 member institutions that all but one claim to need a new system as soon as possible. Being aware that not all members could be covered in a single big step, we decided to establish a group of pilot institutions. It would be probably better if we had divided the members into groups of similar requirements and structure and then taken 
representatives. Unfortunately, this was not possible, since almost any institution had some specifics.

According to the aforementioned strategy plan, the university was expected to develop a single SRIS that would be then installed and used by all the members. But the problem was that in our estimations, such a project would take at least two years, which was simply too long for the majority of university members. We realized that if we had started the development of a common system, we would have taken a chance that the institutions would go their own way developing their own SRIS. In this case, it would be rather difficult to ensure the university would be able to collect all the information that is needed for its processes. Taking into account the doubts and hesitations the university decided for the following steps:

- Firstly, a minimal set of common standards for SRIS have to be developed. The standards must include: a list of core functions the SRIS must support, a common data model (the entities that are required to support the core functions plus entities required to integrate the SRIS with other systems), and a common architecture that will ensure the system stability, security and performance.

- Once the common standards are developed, the implementation of the core functions can be outsourced to several development teams that would than develop SRISs in parallel.

Another major problem was system maintenance. Although the University of Ljubljana has a special organization unit called the University Computer Centre (UCC), which is responsible for UIS administration, maintenance and development, it did not have a good reputation. The unit is simply not capable to cover all the institutions. We must say that the University did not decide yet how it would resolve this problem. As we see the problem, it seems reasonable that each development team that develops a SRIS takes also responsibility for the system maintenance. In this way, the UCC would only need to take care for smaller interventions.

\section{CONCLUSIONS}

Modernization of administrative procedures by introducing $e$-business is necessary for contemporary universities. At the University of Ljubljana we decided to rebuild the existing SRIS using a portal technology, which seems to be today one of the most promising concepts for developing integrated, user-centric IT solutions. In this paper we have briefly introduced the strategy plan that had led into the renovation of SRIS. The renovation was then described in more detail. At the end, we exposed some difficulties that we had to deal with during the project. 


\section{REFERENCES}

Cunin, P.Y., Lacombe, C., Desnos, J.F. \& Lenne, C. (2002). The Portal of “GreCOUniversités". In The Changing Universities: The Challenge of New Technologies Proceedings of the EUNIS'2002 Conference, Santos, J.M. \& Ribeiro, L.M. (ed.), Portugal June.(2002).

Eisler, D. (2000). The Portal's Progress: A Gateway for Access, Information, and Learning Communities, Syllabus Magazine, 14(1). http://www.syllabus.com/syllabusmagazine/sept00_fea.html.

Gartner Group (2000a). Higher Education Enterprise Portals. Gartner Group Research Note, SPA-11-0354

Gartner Group (2000b). JA-SIG's Community-Sourced Portal for Higher Education. Gartner Group Research Note, P-11-9781

Haselbacher, F. (2002). Design and operation of a WEB-databased university-informationmanagement-system. In The Changing Universities: The Challenge of New TechnologiesProceedings of the EUNIS'2002 Conference, Santos, J.M. \& Ribeiro, L.M. (ed.), Portugal, June, 2002.

Krisper, M., Bajec, M., Rupnik, R., Mahnið, V., Rožanec, A., Jaklič, J., Stemberger, M. \& Groznik, A. (2001). Information System Strategy Plan for the University of Ljubljana, University of Ljubljana, Faculty of Computer and Information Science.

Looney, M., \& Lyman, P. (2000)- Portals in Higher Education: What are they, and what is their potential? EDUCAUSE Review, July/August, pp. 28-35

Mahnic, V. \& Vilfan, B (1995). Design of the Student Records Information System at the Univeristy of Ljubljana, In Trends in Academic Information systems in Europe -

Conference Proceedings, J. Knop (ed.), Heinrich-Heine-Universität, Düsseldorf, Germany, November,1995.

Mahnic, V. (2001). Requirements Specification for the first phase of the E-student project, University of Ljubljana, Faculty of Computer and Information Science.

Olsen, F. (2000). Institutions Collaborate on Development of Free Portal Software, The Chronicle of Higher Education, Information Technology, 5, May.

Río, J., Taboada, J.A., Flores, J. \& Gómez-Sobradelo, M.V. (2002) Design of a web-based MIS for the USC using multiple data sources. In The Changing Universities: The Challenge of New Technologies - Proceedings of the EUNIS'2002 Conference, Santos, J.M. \& Ribeiro, L.M. (ed.), Portugal, June, 2002.

Shaw, T., Strachan, A., McCauley, G. \& McCrae, L. (2002). The portal as the framework for the information strategy? In The Changing Universities: The Challenge of New Technologies - Proceedings of the EUNIS'2002 Conference, Santos, J.M. \& Ribeiro, L.M. (ed.), Portugal, June, 2002.

Woods, K., Boice, M. \& Hudson, M. (2002). The Evolution of the Digital Campus. In The Changing Universities: The Challenge of New Technologies - Proceedings of the EUNIS'2002 Conference, Santos, J.M. \& Ribeiro, L.M. (ed.), Portugal, June,2002. 
SECTION 3

THE MANAGEMENT OF E-LEARNING 